\title{
Integrated environmental and hygienic assessment of the region
}

\author{
Anton Martsev, ${ }^{1, *}$ \\ ${ }^{1}$ Vladimir State University named after A.G. and N.G. Stoletovs', 87, Gorky Str., 600000, Vladimir, \\ Russia
}

\begin{abstract}
To determine the ecological and hygienic status of the environment and its possible impact on population health, the issue of developing a comprehensive methodology for integrated assessment of the environment condition, in particular, at the regional level, has been set. The research objective was to develop the methodology for ecological and hygienic integrated assessment of the environment and its individual indicators, and to test it at the separate regional level of the Russian Federation - the Vladimir region, primarily regarding the human life quality. The research is based on the official statistics data published by the Vladimir region administration, "Federal hygiene and epidemiology center of the Vladimir region" for the period of 2001-2015, as well as our own research of the regional environment condition (quality of air, municipal water supply and soil). As the research result, the statistics data of the State offices engaged in social and hygienic monitoring, as well as own environmental surveys, characterizing the quality of atmospheric air, municipal water supply and soil in residential areas were analyzed, and relatively safe and relatively unfavorable environmental areas were identified. The environmental quality analysis and the application of the integrated assessment methodology made it possible to rank the region areas according to the ecological and hygienic well-being rate
\end{abstract}

\section{Introduction}

Nowadays, the environmental pollution and its factors impact on population health is one of the most relevant scientific problems. Numerous researches devoted to this problem [1] draw attention to the diseases initiated by harmful environmental effects. Herewith we mean both the excess of biologically active chemicals entering the body, and their lack. The nation health protection is the main task of social development, which specifies the importance of theoretical and practical formulations in the field of the environmental factors influence on population health and determines the necessity for the research and development of the appropriate recommendations. The environmental contribution to the population health in Russia ranges from 16-54\%, depending on the regional characteristics, according to various scientific opinions [2]. The World Health Organization (WHO) experts say that health is

\footnotetext{
*Corresponding author: martsevaa@yandex.ru
} 
mainly determined by the influence of four groups of factors which contribution in different areas may vary substantially: heredity, environment state, medicine, population lifestyle.

According to the scientists' opinions, recent decades various regions of Russia have been characterized by unfavorable environmental situation. It has been noted that the most unfavorable areas reveal significant habitat deformation and are localized mainly in the European part of the country, in the Urals and in Southern Siberia. Considerable pollution of the industrial centers and population density in these areas are stipulated by the complicated set of environmental problems, such as the forest resources depletion and poor soil fertility, which in turn create a real threat to the environmental safety. According to Yakimova E. A. unreasonable economic activity in these areas results in deep, and in some cases irreversible changes of natural environment, causing the depletion of natural resource potential and hindering further socio-economic development.

The formation of the population pathologies caused by the anthropogenic environmental pollution in some regions of the country approaches critical values. Air, drinking water and soil pollution are considered to be priority environmental risk factors for public health [3-7].

Most published scientific data reflect the analysis of the individual risk factors impact on pathogenesis of nosology forms. However, recently, some studies appear dealing with medical and environmental trends seeking to use not separate indicators, but integral characteristics of the environment quality in relation to its impact on population health. In this regard, to determine the ecological and hygienic condition of the environment and its impact on population health, we set the task of developing comprehensive methodology for integrated assessment of the environment condition, in particular at the regional level.

The research objective is to develop and test an integral ecological and hygienic characteristic of the environment state and its individual components in relation to the human life quality at the level of individual region of the Russian Federation.

\section{Materials and methods}

This research object is environment ecological and hygienic condition of the Vladimir region. The research is based on official statistics data from Vladimir region administration, "Federal hygiene and epidemiology center of the Vladimir region" for the period of 2001-2015, as well as our own research conducted on the basis of Biology and Ecology Department of VISU, concerning the state of environment (quality of atmospheric air, municipal water supply and soil) in the region. Statistical processing of the data set was performed applying the programs Statistica and Microsoft Excel.

The methodological approach to assess the environment quality is based on the research of T. A. Trifonova (2011), V. S. Tikunov [8], S. A, Kurolap (2017), S. V. Ermolaeva (2014) and others and presented the following way:

1. The database development embracing 15-year period (2001-2015) including main criteria for each district environment quality: air pollution from vehicles and stationary sources (average long-term emission factors ratios of Saeta per person (tonnes/person) and area (tonnes $/ \mathrm{km} 2)$ ); the specific ratio of municipal water supply samples not meeting hygienic requirements of sanitary-chemical and microbiological indicators; specific ratio of residential areas soil samples not meeting hygienic requirements of microbiological indicators.

2. Calculation of coefficients (indices) of environment quality criteria for each district of the region:

- Air pollution index from recalculation per person $\mathrm{I}(\mathrm{A} / \mathrm{p})$ in compliance with the formula: $\mathrm{I}(\mathrm{A} / \mathrm{p})=\mathrm{Epi} / \mathrm{\Sigma p}$,

where Epi - average long-term emission load factor per person for the i-district area;

$\Sigma p$ - the average regional ratio of the emission load in recalculation per person. 
- Atmospheric air pollution index from recalculation per area I (A/s) in compliance with the formula: $I(A / s)=E s i / \Sigma s$,

where Esi - average long-term ratio of the emission load per area for i-district of the region;

$\Sigma s$ - the average regional ratio of emission load per person.

- Specific ratio index of municipal drinking water sources samples not meeting hygienic requirements of sanitary and chemical indicators, $\mathrm{I}(\mathrm{W}) \mathrm{s}-\mathrm{ch}$ :

$I(W) s-c h=W h i / \Sigma h$,

where Whi is average annual specific ratio of water samples from municipal drinking water supply sources in i-district not meeting hygienic requirements of sanitary and chemical indicators;

$\Sigma h$ - average regional indicator of average annual ratio of water samples from municipal drinking water supply not meeting hygienic requirements of sanitary and chemical indicators;

- Specific ratio index of water samples from municipal centralized drinking water supply not meeting hygienic requirements of microbiological indices, $\mathrm{I}(\mathrm{W}) \mathrm{m}-\mathrm{b}$ :

$I(W) m-b=W m i / \Sigma m$,

where $W m i$ is average annual specific ratio of samples from municipal drinking water supply of i-district not meeting hygienic requirements of microbiological indicators;

$\Sigma m$ is average regional indicator of average annual specific ratio of water samples from municipal drinking water supply not meeting hygienic requirements of microbiological indicators;

- Specific ratio index of soil samples from residential areas not meeting hygienic requirements of microbiological indices $\mathrm{I}(\mathrm{S}) \mathrm{m}-\mathrm{b}: I(S) m-b=S i / \Sigma$,

where $\mathrm{Si}$ is average specific ratio of soil samples from i-district not meeting hygienic requirements of microbiological indicators;

$\Sigma$ - average regional annual specific ratio of soil samples not meeting hygienic requirements of microbiological indicators.

The method did not include an indicator of soil samples specific ratio from residential areas not meeting hygienic requirements of sanitary and chemical indicators. We consider it repeat the indicator of atmospheric air pollution.

3. The regional factors transformation of environment quality criteria in the ranks. Depending on the environment quality criterion coefficient value, the district was assigned one of the following ranks: "-1", which corresponds to the criterion coefficient value below the average regional indicator (relatively satisfactory environment quality criterion); "0", which corresponds to the criterion coefficient value equal to the regional average; "1", which corresponds to the criterion coefficient above the regional average (relatively unsatisfactory environment quality criterion). In exceptional cases, when the criterion coefficient value significantly exceeded the regional average, the district was assigned the rank "2" (critical environment quality criterion) or higher, depending on the excess degree.

Since any criterion coefficient of the average regional value always equals 1 , the ranking step was calculated using the following formula:

$$
X=(1-\operatorname{Imin}) / 3 \times 2,
$$

Where Imin is the minimum index value in the region.

The values ranges corresponding to the ranking indicators of the environment criteria are shown in table 1.

4. Summing all criteria ranks and receiving an integral indicator of environment quality. The values range of the integrated environmental indicator for a particular area is determined by the number of criteria. The areas of the lowest integral indicator will be characterized by the relatively safe ecological and hygienic condition and conversely. 


\section{Results}

Atmospheric air is a vital component of human habitat. Its quality greatly affects human health. Since human respiratory system very subtly reacts to the pollutants effects, atmospheric pollutants play significant role in the formation of public health indicators.

Our previous research [3] has shown that air pollution is one of the principle factors in the region that negatively affects the population health, especially children. The key role in air pollution in the region is played by the vehicles, which engine emissions increased more than twice over the analyzed period from 2001 to 2015 (61,977 thousand tons in 2001 and 144,4 thousand tons in 2015). In 2015, the share of motor transport in the emissions structure was $80.8 \%$. The main pollutants exhausted into the air as a result of vehicle operation are carbon, nitrogen, sulfur, hydrocarbons and soot.

The stationary sources contribution to the air basin pollution has been noticeably reducing in recent years, though in certain industrial centers of the region they still rank importance and are reflected on population health [9]. It should be noted that the regional center share during the analyzed period accounted for $23 \%$ of pollutants emissions.

Water, as well as air, is a necessary product of human consumption, so its quality significantly determines the population health. Underground aquifers are main sources of municipal water supply in the region. The regional center and the city of Vyazniki are the least provided with underground water, so the water from the surface sources are used for the household and drinking water supply here, which in turn constantly experience high anthropogenic load. In this regard, the water sources quality of municipal drinking water supply in cities and municipal areas differs in both microbiological and sanitary-chemical indicators. The surface water sources make up the main share of samples that do not meet hygienic standards in terms of microbiological indicators. The percentage of non-standard samples of microbiological indicators remains at a very high level $-89.4 \%$ due to the high anthropogenic load. As for the discrepancy in sanitary- chemical indicator, it primarily depends on the content of iron and manganese ions of natural origin in underground water. Moreover some areas of the region are characterized by the excess of fluorine [7].

Soil as a human habitat element is also of great importance. Its quality, which changes mainly depend on the anthropogenic impact, influences human health and living conditions. The soils of residential areas and farmlands are constantly polluted by household waste, waste products of human and agricultural animals, heavy metal salts, agrochemicals and other pollutants, including as a result of sedimentation processes and precipitation from polluted air. The principle causes of soil contamination in the populated areas are: the increasing amount of municipal solid waste, the lack or failure of the approved schemes of cleaning service in the populated areas, high load on landfills and dumps, unauthorized garbage dumps, etc., increased traffic, industrial enterprises, no centralized sewage system in some settlements, poor state of sewage networks. Polluted soil can become secondary pollution source of atmospheric air, water bodies, underground water, vegetarian food and animal foodstuff and thus affect total ecological and hygienic situation. The soil contamination was analyzed only for microbiological indicators (sanitary-bacteriological and sanitaryparasitological), as sanitary-chemical state of the soil (heavy metals content of soil) is a reflection (and in relation to the method, a duplication) of atmospheric air conditions.

Using the described above methodological approach, the administrative districts of the region were ranked according to the environmental and hygienic indicators. According to the ranks summation, integral indicators were received reflecting the ecological and hygienic situation in the region. The analysis results are presented in Table 2. 
Table 1. Range of values and rank of environmental criteria coefficients.

\begin{tabular}{|c|c|c|c|c|}
\hline $\begin{array}{c}\text { Environment } \\
\text { al criteria } \\
\text { index }\end{array}$ & $\begin{array}{c}\text { "-1"- } \\
\text { relatively } \\
\text { satisfactory } \\
\text { quality of } \\
\text { environmenta } \\
\text { l criteria }\end{array}$ & $\begin{array}{c}\text { "0" - } \\
\text { average } \\
\text { regional value } \\
\text { of the } \\
\text { environmental } \\
\text { criteria }\end{array}$ & $\begin{array}{c}\text { "+1" - } \\
\text { relatively poor } \\
\text { quality of the } \\
\text { environmental } \\
\text { criterion }\end{array}$ & $\begin{array}{c}\text { "+2" - } \\
\text { critical quality } \\
\text { environmental } \\
\text { criteria }\end{array}$ \\
\hline$I(A / p)$ & $0.761-0.92$ & $0.921-1.081$ & $1.082-1.242$ & $>1.242$ \\
\hline$I(A / s)$ & $0.231-0.744$ & $0.745-1.258$ & $1.259-1.772$ & $>1.772$ \\
\hline$I(W) \mathrm{c}-c h$ & $0.12-0.71$ & $0.72-1.31$ & $1.32-1.91$ & $>1.91$ \\
\hline$I(W) \mathrm{M}-b$ & $0.333-0.778$ & $0.779-1.224$ & $1.225-1.67$ & $>1.67$ \\
\hline$I(S) \mathrm{M}-b$ & $0-0.703$ & $0.704-1.299$ & $1.3-1.895$ & $>1.895$ \\
\hline
\end{tabular}

\section{Discussion}

According to the research, it was determined that the most favorable environmental and hygienic conditions for the population residence are observed in Petushki district, than the rest districts of the region, where the values of all five analyzed environment criteria are relatively satisfactory (overall rank "-5"). The most unfavorable, in terms of environmental and hygienic conditions for the population residence was the regional center, however, it occurred because of the critical value of the criterion $\mathrm{I}(\mathrm{A} / \mathrm{s})$. This criterion appeared to be 90 times higher than the regional average due to the largest amount of pollutants emitted into the atmosphere in the region and relatively small area.

Table 2. The actual values of the partial coefficients of the criteria and integral indicator of environmental quality.

\begin{tabular}{|l|c|c|c|c|c|c|}
\hline \multicolumn{1}{|c|}{ Area } & $\boldsymbol{I}(\boldsymbol{A} / \boldsymbol{p})$ & $\boldsymbol{I}(\boldsymbol{A} / \boldsymbol{s})$ & $\begin{array}{c}\boldsymbol{I}(\boldsymbol{W}) \\
\mathbf{c}-\boldsymbol{c h}\end{array}$ & $\begin{array}{c}\boldsymbol{I}(\boldsymbol{W}) \\
\boldsymbol{m}-\boldsymbol{b}\end{array}$ & $\begin{array}{c}\boldsymbol{I}(\boldsymbol{S}) \\
\boldsymbol{m}-\boldsymbol{b}\end{array}$ & $\boldsymbol{\Sigma}$ ranks \\
\hline Alexandrovsky & 0.827 & 1.023 & 0.892 & 0.353 & 0.108 & -3 \\
\hline Vyaznikovsky & 1.075 & 0.723 & 0.37 & 0.944 & 1 & -2 \\
\hline Gorokhovetsky & 1.682 & 0.539 & 2.049 & 1.252 & 1 & 4 \\
\hline Goose-crystal & 1.208 & 0.562 & 1.256 & 0.641 & 0 & -2 \\
\hline Kameshkovsky & 0.84 & 0.485 & 1.814 & 1.921 & 2.513 & 3 \\
\hline Kirzhachsky & 1.176 & 0.839 & 1.28 & 0.469 & 0 & -1 \\
\hline Kovrovsky & 0.761 & 1.451 & 0.719 & 1.354 & 1.443 & 2 \\
\hline Kolchuginsky & 0.991 & 0.878 & 1.757 & 0.752 & 0.846 & 0 \\
\hline Melenkovsky & 1.016 & 0.324 & 1.179 & 0.468 & 0.471 & -3 \\
\hline Muromsky & 1.137 & 2.874 & 0.657 & 0.333 & 0.345 & 0 \\
\hline Petushinsky & 0.873 & 0.692 & 0.157 & 0.567 & 0.207 & -5 \\
\hline Selivanovsky & 0.848 & 0.231 & 0.12 & 1.195 & 0.681 & -4 \\
\hline Sobinsky & 1.253 & 0.894 & 1.537 & 1.146 & 1.728 & 4 \\
\hline Sudogda & 1.142 & 0.401 & 1 & 0.439 & 0 & -3 \\
\hline Suzdl & 1.01 & 0.789 & 1.622 & 1.348 & 1.202 & 2 \\
\hline Yuryev-Polsky & 1.129 & 0.438 & 1.377 & 2.148 & 0.915 & 3 \\
\hline Vladimir & 0.963 & 90.897 & 0.844 & 1.412 & 1.177 & 5 \\
\hline
\end{tabular}

The above method does not account for the ratio of the environment criteria values, which application seems reasonable. However, it is worth noting that the environmental factors contribution may differ in various areas, so these coefficients should be determined empirically individually. The presented method can be updated for a certain area. 


\section{Conclusion}

The environmental quality analysis and integrated assessment methods allowed ranking the Vladimir region area according to the degree of ecological and hygienic well-being. This typology of administrative areas with the identification of specific local environmental problems can contribute to the development of relevant administrative and managerial decisions in the field of social and hygienic monitoring at the regional level.

The study was financially supported by the Russian Foundation for Basic Research and the Vladimir Region Administration in the framework of the scientific project No. 17-45330946 p_a «Development of methodological approaches to the assessment and forecasting of the epidemiology of complex natural focal and parasitic diseases in the Vladimir region».

\section{References}

1. V.M. Zakharov, B.A. Revich, I.E. Trofimov, Russian Journal of Developmental Biology 49(1), 12-17 (2018)

2. L.V. Veremchuk, T.T. Vitkina, E.E: Mineeva, T.A. Gvozdenko, M.V. Antonyuk, K.A. Sidletskaya, K.S. Golokhvast, K. Tsarouhas, V.N. Rakitskii, A.M. Tsatsakis, Environmental Pollution 235, 489-496 (2018)

3. T.A. Trifonova, A.A. Martsev, Gigiena i sanitariya 94(4), 14-18 (2015)

4. E.E. Andreeva, G.G. Onishchenko, S.V. Klejn, Analiz riska zdorov'yu 3, 23-34 (2016) DOI: $10.21668 /$ health.risk/2016.3.03

5. S.V. Klejn, S.A. Vekovshinina, A.S. Sboev, Gigiena i sanitariya 95(1), 10-14 (2016) DOI: 10.18821/0016-9900-2016-95-1-10-14

6. T.A. Trifonova, A.A. Podolec, O.G. Selivanov, A.A. Martsev, Teoreticheskaya i prikladnaya ekologiya 2, 94-101 (2018)

7. T.A. Trifonova, A.A. Martsev, O.G. Selivanov, A.A. Podolec, Gigiena i sanitariya 98(7), 701-706 (2019)

8. V.S. Tikunov, O.Y. Chereshnya, Teoreticheskaya i prikladnaya ekologiya 3, 34-38 (2017)

9. A.A. Martsev, T.A. Trifonova, Zdravookhranenie Rossiiskoi Federatsii 2(58), 39-42 (2014) 